\title{
ILLNESS IS WORK: Revisiting the concept of illness careers and recognizing the identity work of patients with ME/CFS
}

\begin{abstract}
The concept of careers has an extensive history in the sociology of health and illness. Among other things, the notion of a career has been used to describe the changing identities of patients diagnosed with mental illness, to identify distinct stages in the progression of various illnesses, and to recognize the cooperative efforts of hospitalized patients. However, the career concept may be reanalyzed as part of an analytical metaphor that makes salient both the agency of people with illnesses and the social structures in which they are enmeshed. This metaphor, ILLNESS IS WORK, can valorize and aid understanding of the identity work and actions of patients with chronic illnesses, particularly illnesses with a low degree of social recognition and medical prestige such as myalgic encephalopathy and chronic fatigue syndrome (ME/CFS).
\end{abstract}

Keywords: Illness career, chronic illness, metaphor theory, ME/CFS, identity, disease prestige Illness careers in the sociology of health and illness

The concept of careers definitively entered the sociology of health and illness in 1961, through Erving Goffman's Asylums. According to the Oxford English Dictionary, there are two main meanings of the term career, one of goal-directed and one of neutral progression through time: of an occupation with opportunities for progress or the time spent in the commitment to such an occupation, and of simple progression through history. In Asylums, Goffman observes a contemporary shift from the first meaning to the second, and that the term career can have a useful analytical function as a tool of typology, i.e. when "unique outcomes are neglected in favor of such changes over time as are basic and common to the members of a social category, although occurring independently to each of them" (Goffman, 1961, p. 127). In this view, a "career" as a mental patient is not something at which individuals succeed or fail, though it is a progression through different stages of social meaning.

Goffman adopted the term career not only because its "neutral progression" sense made it apt for social taxonomy, but because it had another duality of meaning that united internal and external aspects of identity formation. Unique individuals have uniquely personal careers, but a career is simultaneously a public fact subject to public regulation, which means that a well-developed concept of career "[...] allows one to move back and forth between the personal and the public, between the self and its significant society, without having to rely overly for data upon what the person says he thinks he imagines himself to be" (Goffman, 1961, p. 127). As applied to "mental patients" and further specified as "moral career", it describes the way that people's standards for understanding and judging themselves change when they are institutionalized in mental hospitals; as an observable, typical pattern of reaction to external, institutional circumstances, this concept of "career" works to bring out otherwise inaccessible analytical objects.

Subsequent sociological uses of the career concept have prioritized the reactive, "neutral progression" meaning. Use of the alternative, "goal-directed progression" sense of career is often tinged with irony, as when it is applied in the analysis of marginal or unconventional jobs, criminal pursuits, and drug use, in addition to work in the tradition of Asylums (Aneshensel, 2013). This tendency includes the development of the career concept relative to somatic chronic illness, where it has been used to describe stages of deterioration and institutional descent (Fisher, 1987; Price, 1996), though also to make visible the institutionally unrecognized work performed by hospitalized patients (Strauss, Fagerhaugh, Suczek, \& Wiener, 1982). Here, too, career is used in its "neutral progression" sense, to distinguish stages in the life course of individuals with particular chronic illnesses. Goffman's use of 
the concept remains influential. For Sim \& Madden (2008), different stages form a career since they carrying different meanings for patients and the people with whom they interact. In the sociology of health and illness, then, it seems at the career concept, though it has to some degree been used to account for the work and recognize the agency of patients, remains chiefly taxonomic and typological, in that it is used to describe successive stages in illness development through which patients pass.

There is a case, however, for reinvigorating the "goal-directed progression" sense of the term, in order to better understand how patients actively seek meaningful identities for themselves over time. This entails a conceptual and analytical shift, away from institutional frameworks and towards individuals' life-worlds. Illness careers - the central term in this essay - are dynamic experiential trajectories that encompass many social arenas, though they are certainly shaped by institutions, as well as by other aspects of medical discourse. With this shift, the illness career concept can help explain the activities and attitudes of some patients with chronic illness, particularly those who strive for meaning in the face of diagnostic ambiguity, those who have received an epistemologically or institutionally problematic diagnosis, and those who have a diagnosis with a low degree of social recognition and medical prestige. All three factors are present in the case of myalgic encephalopathy and chronic fatigue syndrome; here, patients' attempts to make meaning by advancing their illness careers may also help explain the sometimes very fraught relationships between such patients and health professionals.

\section{Individual agency and structural instability: The case of ME/CFS}

The "goal-directed progression" sense of illness careers may appear incompatible with the view of illness as the result of external and uncontrollable events. Viewing a career as a goal-directed progression that can succeed as well as fail entails seeing some degree both of agency for the person in question and of malleability in that person's social environment. Those circumstances sometimes apply, but not always. The effects of some illnesses vary more with patient lifestyle choices than others, while a greater range of treatment strategies is available for some illnesses than for others. Moreover, an illness need not always be diagnosed in the same way.

Each of these three factors apply in a particular case, that of the diagnostic complex known as myalgic encephalopathy and chronic fatigue syndrome (ME/CFS), which will serve here as an exemplar for the significance of illness careers. The choice of ME/CFS as an exemplar derives from the empirical background for this essay, namely an investigation into disease prestige and informal medical priorities in Norway. Particular attention was directed by this author at chronic illnesses and permanent impairments. Previous work shows that these categories are often seen by the medical community as having low status and prestige (Album \& Westin, 2008). Surveys of people familiar with the field of impairment and chronic illness [BLINDED REFERENCE 2015], and studies of the discourse and diagnostic systems of ME/CFS [BLINDED REFERENCE 2013 AND 2014], suggest that the conditions of both a malleable environment and a degree of personal agency are present in the case of ME/CFS. Put differently, with this diagnostic complex it is possible as well as conducive to insight to talk about illness careers in the "goal-directed progression" sense.

The scope for individual agency derives in part from diagnostic ambiguity. The label ME/CFS may refer to a single, poorly understood disease, but may also refer to a set of different diseases that have overlapping symptoms but cannot (yet) be clearly distinguished from each other (Jason, Sunnquist, Brown, \& Reed, 2015; Jason, Taylor, Plioplys, Stepanek, \& Shlaes, 2002). Many patients 
who have an illness that relates to the ME/CFS diagnostic complex, i.e. that have symptoms consistent with either ME or CFS, have over the last few decades effectively been faced with the decision to accept, reject, and identify or not identify with one of several diagnostic labels. This decision is not of course theirs exclusively, but the combination of a wide range of available clinical opinion, many different sets of diagnostic criteria, and uncertain courses of progression and treatment, means that the decision process is unusually ambiguous.

From the same set of circumstances derives a degree of structural malleability. In Norway, the largest patients' rights organization in the ME/CFS field strongly advocates not only consistent use of the ME label rather than CFS, but also an emphasis on the purely somatic character of the (presumed) underlying disease (The Norwegian ME Association, 2012). Within medicine, there are multiple etiological hypotheses about ME as well as CFS; patients' rights organizations and individual patients, next-of-kin, and activists regularly engage in the etiological debates. As an example, for people who endorse a somatic explanation, one of the most problematic figures in the ME/CFS field is the psychiatrist Simon Wessely, who has argued for some time that there are strong cultural historical links between ME/CFS and neurasthenia, a disease prevalent in the $19^{\text {th }}$ century and associated with the emergence of neurology, but since relegated to the edges of psychosomatic medicine (Wessely, 1990). By contrast, recent research based on an autoimmune hypothesis has been endorsed, promoted, and crowdfunded by the ME/CFS patient community in Norway (Gjerpe, 2013).

In short, ME/CFS is highly contested, and lies at the intersection of the interests of various medical disciplines, medical bureaucracies, and patients' organizations. It therefore also constitutes an arena where individuals with relevant chronic illness may perceive that diagnoses and even the epistemology of their illness in flux. They are faced, in a somewhat more literal way than the words initially suggest, with the prospect of having to build an illness career. The question of what constitutes criteria for career success or failure can partly be answered with the concept of disease prestige.

\section{Disease prestige and hierarchies of valuation}

The term disease prestige was coined to describe the informal hierarchical ranking of diseases among doctors (Album \& Westin, 2008). Doctors consistently rank some diseases as more prestigious than others. Prestigious diseases appear to be related to medical specialties with high occupational prestige, but both the medical specialties and the diseases are in turn related to particular features of the diseases' its location in the body and its typical patient. High-prestige diseases are often located in specific organs high up in the body, particularly the brain or the heart, while low-prestige diseases are often located low in the body or not in a particular organ. High-prestige diseases often strike patients that are young and male, while low prestige diseases are more often typified by older, female patients. Low-prestige diseases are more often chronic and not acutely life-threatening.

Not only are some conditions seen as more prestigious than others, but different names for similar symptom clusters may carry different levels of prestige: more clinical-sounding diagnostic labels connote higher prestige (Jason et al., 2002). This, too, may contribute to the perception of structural malleability. Studies in the sociology of diagnosis remind us that diagnoses are not static categories, but change over time in accordance with medical as well as non-medical developments (Brown, 1990, 1995; Jutel, 2009, 2015). People who are chronically ill, and this appears very much to be the case with ME/CFS patients, may be aware not only that the kind of illness they are recognized as having 
will influence the kind of attitudes they will encounter and the treatment they will receive, but that alternatives are possible.

In some cases prestige is not in itself a very important factor, because it is impossible for patients to change both the kind of illness they have and the prestige level with which it is associated. The first of these facts will be changed mainly in cases of misdiagnosis, while the second fact will likely change rather slowly. There are cases in which diseases gradually lose their cultural stigma, with cancer as perhaps the most salient example (Mukherjee, 2010), but prestige levels appear to be sociocultural constructs that are relatively stable over time [BLINDED REFERENCE 1990, 2008 AND 2015]. In cases where this holds, disease prestige may appear a function mostly of the cultural valorization of certain properties: masculinity, organ functions such as cognition, medico-technical expertise, the drama of life-and-death situations, etcetera. This makes the issue of illness careers for individuals, if not moot, then at reducible to the "neutral progression" sense of the term. But there are other cases.

$\mathrm{ME} / \mathrm{CFS}$ represents a different set of circumstances. Here, with diseases that have low prestige and are linked to chronic illness, to patients with lower social status, and to ambiguous etiologies that may have psychosomatic components, higher disease prestige and a successful illness career may, in lieu of an actual cure, be viewed as a legitimate goal both structurally and for individuals. Under such conditions, it may be deemed strategic to make explicit comparisons between patients from one's own diagnostic group and patients with other diagnoses. Of course, an overriding motivation for patients with ME/CFS, as for all other patients, is to get effective treatment. ME/CFS is notable mainly for the comparisons made with diagnoses that are generally considered more severe, such as cancer:

\section{Cancer and autoimmune disease patients get Rituximab every three to six months to maintain their healthy condition. I know that my time being well is limited, and I'm using all my regained health to make sure the science continues.' (Gjerpe, 2013)}

\section{Illness as metaphor: The function of analytical comparisons}

We should remind ourselves that the use of the term career in the field of health and illness is usually - though not necessarily - a metaphor. People can quite literally make a career out of being ill by drawing on their experience, e.g. as patient experts and collaborators, as speakers, and as authors. However, such literal illness careers are circumscribed in ways that do not apply to a career as, say, a lawyer. They rarely provide a full income, there are far less defined levels of competency, and the role of "professional patient" cannot exist independently of personal biography in the same way as the role of "legal professional". The primary sense of career, i.e. an occupational undertaking with the possibility of advancement, is therefore most useful in the effort to understand the experience of being ill by way comparing and contrasting certain aspects of the two topics, not by positing a full identification of the two.

Another way to phrase this analytical operation - selective comparison and contrast - is to borrow the terminology of metaphor theory (Kövecses \& Csábi, 2002; Lakoff \& Johnson, 1980; Lakoff \& Turner, 1989), where metaphor is understood as a cognitive connection between one cognitive domain and another. The term career belongs to the domain of work and professions; when it is used outside that domain, the use is metaphorical, whether the new domain is that of criminal pursuits or 
that of illness experience. In metaphor theory, the domain of literal use is the source domain, while the domain of metaphorical use is the target domain.

This entails that a metaphor is something more than a surface feature of language; it is a cognitive operation in which the structures and features of the source domain is used to understand and conceptualize the target domain. The career metaphor is therefore not necessarily dependent on use of the word "career" itself, but may be expressed with a range of words and phrases that, in metaphor theoretical shorthand, relate to the metaphor ILLNESS IS A CAREER. From the perspective of metaphor theory, noting that e.g.. drug use and addiction can be understood in terms of career-like progression (Becker, 1953) also counts as use of an analytical metaphor.

Metaphor theory posits that metaphorical connections tend to be established between source domains that are concrete, familiar, and highly structured, and target domains that are abstract, chaotic and difficult to conceptualize. In such cases, comprehension of the source domain serves as an aid to understanding the target domain. For example, the relatively concrete and comprehensible domain of journeys and travel may be used to comprehend the much more abstract domain of human existence or life with the metaphor LIFE IS A JOURNEY. Configuring life as a journey is a familiar and indeed tired metaphorical strategy, but it is mostly comprehensible and in certain cases very useful, insofar as it imposes direction, goals, and a certain degree of predictability in progression.

Of course, life is not literally a journey. It cannot be lived backwards, and while a person may go on several journeys, he or she will only experience one lifetime. This is a crucial postulate in metaphor theory. Metaphors aid understanding by simultaneously highlighting and obscuring different aspects of both the source and the target domain. It is precisely because of this mechanism that metaphors are an effective strategy for comprehension, for if there was perfect overlap between the source and target domains (if life was literally like a journey), then there the connection between them would yield no new information.

An analytical metaphor, therefore, ILLNESS IS A CAREER is interesting partly because it diverges from another metaphor - the culturally salient understanding that ILLNESS IS WAR. Following both Lakoff \& Johnson and the seminal essays of Susan Sontag on cancer and AIDS (Sontag, 1991), it has long been clear that illness is often viewed, talked about, and thought about, in terms of invasion, conflict, and battle. People or their immune systems "fight" against illness, bacteria, and other enemies; they lose or win "battles", they are aided by their doctor "allies" and can be "betrayed" by their own bodies.

Many common metaphors, with ILLNESS IS WAR as a prime example, have profound implications for how we frame complex phenomena. The notion that illness is a conflict confers a considerable degree of moral responsibility upon the patient, who is put in the position of having to either carry on or give up the fight. Moreover, ILLNESS IS WAR, when seen in conjunction with the hierarchies and mechanisms of disease prestige, has troubling implications for many people with chronic illness. Chronic illness presents the patient as well as the doctors with a battle that cannot be won and a fight that never ends.

The meaning in metaphors: Recognizing the work of being ill

IIIness is often accompanied by a search for meaning. Often this search takes the form of narrative work, in which patients look for a story that give their experiences sense and shape (Frank, 2010; 
Kleinman, 1989). But narratives, like war, constitute a source domain with certain inherent structures. Narratives are finite, and they conventionally have a clearly delimited arc - a beginning and a middle, as well as an end. They may be well suited for conceptualizing discrete episodes, but they may be of more limited value in conceptualizing illness experience that stretches over a very long time, perhaps even a whole lifetime.

A career, too, must come to an end, although there are people lucky enough to have a career that lasts a lifetime. Still, it might be better to replace the metaphor ILLNESS IS A CAREER with the more wideranging metaphor ILLNESS IS WORK. In this metaphor, the "neutral progression" sense of career is largely irrelevant, but the "goal-directed progression" sense becomes quite significant. If ILLNESS IS WORK - and this is the contention of many scholars, not least Strauss et al. (1982) - then an illness career is a possible but not a necessary way to shape one's understanding of that work; in the source domain of WORK, a career is usually distinguished from simply having a job. There is little conflict with Goffmann here; both the identity negotiations of patients in mental hospitals and other psychiatric settings, and the collaborative efforts of hospitalized patients may be productively seen as work.

The work associated with illness brings rewards mostly in the form of absence of trouble, rather than monetary benefits, but these rewards are no less real. Such work is increasingly seen as a productive topic for research; in one taxonomy, it may be classified as belonging to the domains of illnessspecific work, the domain of maintenance of everyday routines, and the domain of emotions and personal relationships (Vassilev et al., 2013). In each case, there are benefits to doing the tasks associated with each domain, and drawbacks to not doing them. They are forms of goal-directed persistent effort, with the possibility of remuneration - not literally, but metaphorically.

The analytical metaphor ILLNESS IS WORK foregrounds the dynamic and temporal aspects of the illness experience. It explains the activities of patients who relate to the ME/CFS complex - their high level of engagement in both the public sphere and in medical forums (Knudsen et al., 2012), their crowdfunding efforts, and their strong opinions about diagnostic categories and etiologies (Bjerkestrand, 2012) - as a way to engage in the meaningful activity of illness career building. The Norwegian ME Association, in its statement on the nature of ME, stresses that it "supports a biomedical approach to ME [... and has] consistently supported biomedical research, documentation, and treatment, as long as they are based on science." (The Norwegian ME Association, 2012)

Being sick - specifically, entering into the sick role (Parsons, 1975, 2013; Varul, 2010) - is easily framed as a form of retreat into passivity. Outside of periods of incapacitation, however, the illness experience may be anything but passive. In the sociology of mental illness, the typical illness career may be modeled as a quest "to figure out what is wrong, what to name it, what to do about it, and, ultimately, how to live with it" (Aneshensel, 2013, p. 605). This may very well take the form of adaptation to a pre-existing medical model. Crucially, however, the career metaphor allows that "a number of alternative career paths exist. Many people develop symptoms of psychological disorder in some shape or form, but only some become psychiatric patients beset by recurrent episodes of impairment." (Aneshensel, 2013, p. 605)

The model fits well with ILLNESS IS WORK (though it perhaps underplays the agency of patients). It also reflects back upon the connection between illness careers and low disease prestige. The multitude of available paths may be central both to the work of mental illness and to the work of ME/CFS. The criterion overlap between DSM diagnoses is a highly complex topic in its own right; for these 
purposes, I will merely note that to a much greater extent than the diagnosis of somatic diseases that exhibit clear biomarkers, diagnosis of mental illness entails a clinical choice between partly intertwining paths. The ME/CFS diagnostic complex, too, may contain different pathways for the same patient, depending both on that patient's point of entry into the complex (i.e. his or her initial contact with a medical professional) and on subsequent developments. Given the lack of diagnostic certitude, it is perhaps not surprising that the patients' experiences are routinely characterized both by uncertainty and by strong desire for meaning. ME/CFS illness experiences may thus verbally manifest as Arthur Frank's "chaos narratives" (Frank, 2010), detailing the uncertainty, but also as attempts to build a more successful illness career.

\section{ILLNESS IS WORK and medicalization}

The sociological function of ILLNESS IS WORK is perhaps most clearly seen in light of the World Health Organization's definition of health. If health is the state of "complete physical, mental and social well-being and not merely the absence of disease or infirmity" (World Health Organization, 1948), then we all have illness careers to attend to. Humans are unlikely to win the battle for complete wellbeing any time soon; for now, there is work to do.

Although the case of ME/CFS may turn out to have limited applicability as a template for illness career paths, it and the metaphor ILLNESS IS WORK shed further light on the disease prestige hierarchy. Somatic, unambiguously located diseases are at the top, while epistemologically problematic chronic conditions are at the bottom. If one doesn't have a disease at the top, then it would perhaps be wise to act as if one did - in other words, to dress for the job one wants rather than the job one has. This means, generally speaking, striving for medicalization (Conrad, 2008). The phenomenon is culturally pervasive, nowhere more so than in psychiatry. Ever since the DSM-III, psychiatry has striven towards medicalization, or, to put it another way, towards greater disease prestige by way of medicalization. It should not be surprising that patients have picked up on this trend, and that people who enter the $\mathrm{ME} / \mathrm{CFS}$ diagnostic complex recognize that having a somatic illness is in many ways preferable to having a psychiatric illness. Greater presumptions of curability might be a factor, as might a lesser presumption by others that one is morally responsible for one's condition - a presumption that continues to dog people with psychosomatically explained diagnoses.

A successful illness career for a person with symptoms consistent with ME/CFS would then consist, if not in getting well, then in establishing an understanding of one's illness where the underlying problem is somatic and the onus of improvement is chiefly or entirely on medical professionals rather than patients - i.e., where one isn't "sleeping on the job". The topics of motivation and patient behavioral patterns that hinder or further improvement are common to ME/CFS discourse; cognitivebehavioral therapy is advanced by many practitioners, and there has been, in Norway, a considerable controversy over the Lightning Process, a CBT-inspired commercial course format that is regularly promoted as an effective self-management intervention for people with ME/CFS. The actual efficacy of the Lightning Process is unclear (Reme, Archer, \& Chalder, 2012), but many ME/CFS patients see it as potentially harmful and as a threat both to their identities as somatic patients and to potential advancement towards other, more effective treatments (Hawkes, 2011).

Having an illness inevitably involves a large amount of quite literal effort. Some of this effort is personal, relating to personal needs and routines. As with many chronic illnesses, the symptoms common to ME/CFS, including fatigue, cognitive problems and sensory hypersensitivity, entail that 
everyday tasks can become very taxing. Some of the effort is relational. Chronic illness means ongoing contact not only with many people in the health services, but also with various bureaucracies that control quasi-medical services and/or insurance schemes, as well as with employers and HR departments (for people working) or with unemployment agencies. Being ill requires justification and documentation - the first of one's rights and relative privileges, the second of one's body and its ailments. These efforts are not minor or casual. They can be demoralizing, exhausting, and a cause for despair. Structuring them as work may be a strategy for providing meaning where little meaning is apparent.

\section{Conclusion: The inevitability of illness work and the social function of illness careers}

To health professionals, as Strauss et.al (1982) point out, patient work often reads as compliance. Countless micro-interactions between patients and health professionals require patients to move or position their bodies in certain ways, to respond to questions or otherwise provide information, to cooperate with health professionals who have tasks to complete. But patients with chronic illnesses are also responsible for monitoring their condition, initiating contact with health professionals, following up when appointments are rescheduled or delayed, i.e. performing administrative work in tandem with the health bureaucracies and professionals that they depend upon. "Compliance" does not accurately describe these efforts, because they require patients to maintain vigilance and exert agency.

If work is understood as any form of activity that involves mental or physical effort directed at a result, then these actions are certainly work. A more restrictive definition might involve, for example, effort only in exchange for payment or effort likely to produce surplus value, but even in such cases, patient work will still count as work. The payment or surplus value might not be as directly attached to the effort as would be true of effort expended at an assembly line, but economic concerns are highly relevant both to patients and health care professionals. A patient who does not "comply" or cooperate in order to reach treatment goals is likely to be viewed as a problem for the health bureaucracy as a whole, and indeed for much of society, unless he or she simply goes away, which is rarely the case.

The point of these observations is that ILLNESS IS WORK may be quite useful in capturing the sense of individual responsibility experienced by patients with chronic illness, as well as the need for their continuous effort - even, and perhaps particularly, when these are not explicitly recognized by others. It may help explain their motivation and actions, including when their actions are or appear to be in conflict with professional medical opinion and advice. The notion of a purposeful trajectory marks a clear distinction from passive patient roles while recognizing work that is already being performed as work. People with chronic illness strive for recognition of their experiences, their competence, and their embodied knowledge of themselves and their own illness; this effort may be tightly interwoven with the struggle towards health, but does not entail an expectation to become free of all illness and experience total well-being.

The need for an analytical understanding that ILLNESS IS WORK may be particularly strong in cases where an illness' etiology is incomplete or lacking because there are in such cases less recognition of patients' work to begin with. When the medical vocabulary does not explain what is going on, the vocabulary of everyday life will have to suffice, but it will not necessarily be a source of recognition in a medical setting. In the case of ME/CFS, with salient symptoms such as fatigue, a great deal of 
patient work is related to everyday life management, rather than e.g. compliance with specific medical procedures. Such work may be quite difficult to recognize as work, even if it constitutes sustained, significant and purposeful effort over a considerable amount of time.

In conclusion, the point of this essay has been to recognize that the professionalization of people with chronic illness is already a normative force in the world, and thus to name and describe the analytical position that ILLNESS IS WORK so it can be both recognized and critiqued. It seems probable or at least possible that such recognition may be a good thing for many people with chronic illness, at least to the extent that it functions as a conduit for empowerment and self-determination. The normative forces that demand patient efforts may also be experienced as oppressive. While the classical sick role may be problematic for its association with stigma and suspicion, the active sick role, the onus of building an illness career, may place people with chronic illness, when they are at their most vulnerable and have the least resources, in a double bind. It should be incumbent upon health bureaucracies, services, and professionals, to examine the normative expectations with which patients are met, and the metaphorical glasses through which they are viewed. 
ILLNESS IS WORK

\section{Literature}

Album, D., \& Westin, S. (2008). Do diseases have a prestige hierarchy? A survey among physicians and medical students. Social Science \& Medicine, 66(1), 182-188. doi:10.1016/j.socscimed.2007.07.003

Aneshensel, C. (2013). Mental illness as a career: Sociological perspectives. Handbook of the Sociology of Mental Health. Retrieved from http://link.springer.com/chapter/10.1007/978-94-007-4276-5_29

Becker, H. (1953). Becoming a marihuana user. American Journal of Sociology. Retrieved from http://www.jstor.org/stable/2771989

Bjerkestrand, S. (2012). Maktskiftet [“Power shift”]. Tidsskrift for Den Norske Legeforening, 132(2), 125. Retrieved from http://tidsskriftet.no/article/2200325

Brown, P. (1990). The name game: toward a sociology of diagnosis. The Journal of Mind and Behaviour, 11(3-4), $385[139]-406[160]$.

Brown, P. (1995). Naming and framing: the social construction of diagnosis and illness. J Health Soc Behav, 35(Special issue), 34-52.

Conrad, P. (2008). The Medicalization of Society: On the Transformation of Human Conditions into Treatable Disorders. JHU Press.

Fisher, B. J. (1987). Illness career descent in institutions for the elderly. Qualitative Sociology, 10(2), 132-145. doi:10.1007/BF00988525

Frank, A. W. (2010). The wounded storyteller: Body, illness, and ethics. Chicago: University of Chicago Press.

Gjerpe. (2013). MEandYou. Retrieved from http://www.meyou.no/

Goffman, E. (1961). Asylums. Harmondsworth: Penguin.

Hawkes, N. (2011). Dangers of research into chronic fatigue syndrome. BMJ (Clinical Research Ed.), 342(jun22_1), d3780. doi:10.1136/bmj.d3780

Jason, L. A., Sunnquist, M., Brown, A., \& Reed, J. (2015). Defining Essential Features of Myalgic Encephalomyelitis and Chronic Fatigue Syndrome. Journal of Human Behavior in the Social Environment, 25(6), 657-674. doi:10.1080/10911359.2015.1011256

Jason, L. A., Taylor, R. R., Plioplys, S., Stepanek, Z., \& Shlaes, J. (2002). Evaluating Attributions for an Illness Based Upon the Name: Chronic Fatigue Syndrome, Myalgic Encephalopathy and Florence Nightingale Disease. American Journal of Community Psychology, 30(1), 133-148. doi:10.1023/a:1014328319297

Jutel, A. (2009). Sociology of diagnosis: a preliminary review. Sociology of Health \& Illness, 31(2), $278-299$. doi:10.1111/j.1467-9566.2008.01152.x

Jutel, A. (2015). Beyond the Sociology of Diagnosis. Sociology Compass, 9(9), 841-852. doi:10.1111/soc4.12296

Kleinman, A. (1989). The illness narratives: Suffering, healing, and the human condition. Basic Books.

Knudsen, A. K., Lervik, L. V, Harvey, S. B., Løvvik, C. M. S., Omenås, A. N., \& Mykletun, A. (2012). Comparison of chronic fatigue syndrome/myalgic encephalopathy with other disorders: an observational study. JRSM Short Reports, 3(5).

Kövecses, Z., \& Csábi, S. (2002). Metaphor : a practical introduction. Oxford: Oxford University Press.

Lakoff, G., \& Johnson, M. (1980). Metaphors We Live By. Chicago: University of Chicago Press. 
ILLNESS IS WORK

Lakoff, G., \& Turner, M. (1989). More Than Cool Reason: A Field Guide to Poetic Metaphor. Chicago: University of Chicago Press.

Mukherjee, S. (2010). The emperor of all maladies : a biography of cancer. New York: Scribner.

Parsons, T. (1975). The sick role and the role of the physician reconsidered. The Milbank Memorial Fund Quarterly. Health and Society, 257-278.

Parsons, T. (2013). The Social System. London: Routledge.

Price, B. (1996). Illness careers: the chronic illness experience. Journal of Advanced Nursing. Retrieved from http://onlinelibrary.wiley.com/doi/10.1046/j.1365-2648.1996.02047.x/full

Reme, S. E., Archer, N., \& Chalder, T. (2012). Experiences of young people who have undergone the Lightning Process to treat Chronic Fatigue Syndrome - a Qualitative Study. British Journal of Health Psychology, 18(3), 508-525.

Sim, J., \& Madden, S. (2008). Illness experience in fibromyalgia syndrome: a metasynthesis of qualitative studies. Social Science \& Medicine (1982), 67(1), 57-67. doi:10.1016/j.socscimed.2008.03.003

Sontag, S. (1991). IIIness as Metaphor and AIDS and Its Metaphors. London: Penguin.

Strauss, A. L., Fagerhaugh, S., Suczek, B., \& Wiener, C. (1982). The work of hospitalized patients. Social Science and Medicine, 16(9), 977-986. doi:10.1016/0277-9536(82)90366-5

The Norwegian ME Association. (2012). The Norwegian ME Association. Retrieved from http://meforeningen.com/meforeningen/

Varul, M. Z. (2010). Talcott Parsons, the Sick Role and Chronic Illness. Body \& Society, 16(2), 72-94. doi:10.1177/1357034X10364766

Vassilev, I., Rogers, A., Blickem, C., Brooks, H., Kapadia, D., Kennedy, A., ... Reeves, D. (2013). Social networks, the "work" and work force of chronic illness self-management: a survey analysis of personal communities. PloS One, 8(4), e59723. doi:10.1371/journal.pone.0059723

Wessely, S. (1990). Old wine in new bottles: neurasthenia and "ME." Psychological Medicine, 20(01), 35-53. doi:doi:10.1017/S0033291700013210

World Health Organization. (1948). Preamble to the Constitution of the World Health Organization as adopted by the International Health Conference, New York, 19-22 June, 1946; signed on 22 July 1946 by the representatives of 61 States (Official Records of the World Health Organization, no. 